\title{
RUNX1/MECOM Fusion Protein
}

National Cancer Institute

\section{Source}

National Cancer Institute. RUNX1/MECOM Fusion Protein. NCI Thesaurus. Code C99296.

A fusion protein (1395 aa, 156 kDa) encoded by the RUNX1/MECOM fusion gene. This protein is comprised of the $\mathrm{N}$-terminal runt domain of the runt-related transcription factor 1 protein fused to the MDS1 and EVI1 complex locus protein EVI1 isoform 2 protein. 